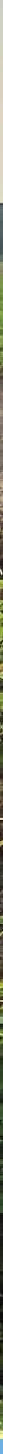

Efficacy to control potato late blight by applying biological crop protection products

EuroBlight field experiment AGV7716

A. Evenhuis \& H.T.A.M. Schepers | Wageningen Plant \& Research |

\title{
WAGENINGEN
}

UNIVERSITY \& RESEARCH 


\section{Efficacy to control potato late blight by applying biological crop protection products}

EuroBlight field experiment AGV7716

A. Evenhuis \& H.T.A.M. Schepers

This study was carried out by the Wageningen Research Foundation (WR) business unit Field Crops and was commissioned and financed by EuroBlight participants.

WR is part of Wageningen University \& Research, the collaboration of Wageningen University and Wageningen Research Foundation.

Wageningen, December 2020

WPR Report 868 
A. Evenhuis \& H.T.A.M. Schepers, 2020. Efficacy to control potato late blight by applying biological crop protection products Wageningen Research

This report can be downloaded for free at https://doi.org/10.18174/ 541281

(C) 2020 Wageningen, Stichting Wageningen Research, Wageningen Plant Research, Business Unit Field Crops P.O. Box 430, 8200 AA Lelystad, The Netherlands; T +31 (0)300 2911 11; www.wur.eu/plantresearch

Chamber of Commerce no. 09098104 at Arnhem

VAT NL no. 8065.11.618.B01

Stichting Wageningen Research. All rights reserved. No part of this publication may be reproduced, stored in an automated database, or transmitted, in any form or by any means, whether electronically, mechanically, through photocopying, recording or otherwise, without the prior written consent of the Stichting Wageningen Research.

Stichting Wageningen Research is not liable for any adverse consequences resulting from the use of data from this publication. 


\section{Contents}

1

$\begin{array}{ll}\text { Introduction } & \mathbf{5}\end{array}$

1.1 EuroBlight Table $\quad 5$

1.2 EuroBlight table set-up for low risk products $\quad 5$

2

$\begin{array}{ll}\text { Methods and materials } & 6\end{array}$

2.1 Experimental set up. 6

2.2 Treatments $\quad 6$

2.3 Inoculation $P$. infestans $\quad 7$

$\begin{array}{lll}2.4 & \text { Disease observations and Yield } & 7\end{array}$

$\begin{array}{lll}2.5 & \text { Statistics } & 7\end{array}$

\begin{tabular}{l|lr}
3 & Results & 8
\end{tabular}

3.1 Potato late blight severity 10

$\begin{array}{ll}3.2 & \text { Tuber blight and yield } \\ \end{array}$

4 Discussion and conclusions 12

4.1 Potato late blight $\quad 12$

4.2 Tuber blight $\quad 12$

4.3 Yield 12

4.4 Conclusions 13

$\begin{array}{lll}\text { Annex } 1 & \text { Trial lay-out } & 14\end{array}$

$\begin{array}{lll}\text { Annex } 2 & \text { NVWA certificate } & 16\end{array}$

$\begin{array}{lll}\text { Annex } 3 & \text { Disease observations PLB } & 17\end{array}$

$\begin{array}{lll}\text { Annex } 4 & \text { Yield and tuber blight } & 18\end{array}$

$\begin{array}{lll}\text { Annex } 5 & \text { Weather data Lelystad } & 19\end{array}$ 


\section{Introduction}

\section{$1.1 \quad$ EuroBlight Table}

Late blight caused by Phytophthora infestans is the most important foliar disease in the cultivation of potatoes. The crop needs to be protected from $P$. infestans by spraying fungicides regularly during the growing season. It is important to use fungicides that effectively protect leaves against this disease. A whole range of fungicides was or became registered in the last years. Each fungicide has its own mode of action and efficacies and therefore has specific characteristics. To evaluate each characteristic a EuroBlight table was set up to get an overview of the value of each characteristic. Up until the Bologna meeting in 2007, the ratings are based upon expert judgement, from both agrochemical companies and independent researchers. To evaluate the effectiveness of fungicides harmonised protocols were discussed at Tallinn. It was proposed that ratings of fungicides for the EU-table are calculated when field experiments are carried out over 2 years in 3 European countries. Each year from 2006 to 2019 at least three experiments were carried out. In fact 43 field experiments were set up to compare the effectiveness against leaf late blight by measuring the protection of leaves from application of a fungicide in a standard 7-day spray schedule (this standard spray schedule is not necessarily related to the label recommendations). This protection originates from the protectant and/or curative properties of the active ingredients and in the rapid growth phase of the crop also protection of new growth can contribute to the effectiveness of the fungicide for leaf blight control. Dose rates were the highest preventative doses registered in Europe. The results of the trials were used to re-evaluate the effectiveness of fungicides to control potato late blight.

\subsection{EuroBlight table set-up for low risk products}

Nowadays a growing public concern on using synthetic crop protection products has led to the search for new and biological crop protection products (BCPP) with low risk to the environment. In literature products from bacterial origin, plant extracts, salts etc are described and claim to control $P$. infestans. Within the EuroBlight network, an initiative was taken to set up an experiment to rate the biological crop protection products similarly to the EuroBlight table for fungicides. Since it is expected that these products will be less effective than synthetic fungicides the set-up of the experiment was adjusted. Major adjustments in comparison to the EuroBlight experiment are:

- $\quad$ The cultivar is medium susceptible to potato late blight

- The potato crop is not inoculated. Infection relies on natural sources

- $\quad$ No spreader rows are set-up in the experiment

- $\quad$ No sprinkler irrigation to facilitate the late blight epidemic is used. Irrigation for the purpose of supplying water in case of drought is allowed.

- $\quad$ The untreated control is allotted randomly to the block design

This report describes the efficacy of biological plant protection products to control potato late blight during the whole season of the 2019 experiment at Lelystad (NL).

Because the results are confidential the treatments are not given in this report. 


\section{$2 \quad$ Methods and materials}

\section{$2.1 \quad$ Experimental set up.}

The cultivated potato plants (cv. Agria) were grown at Wageningen University and Research location Lelystad. The experiment was treated conform local good agricultural practice, only the fungicide sprayings against $P$. infestans were carried out as mentioned in Table 1 . A plot consisted of 3 meters (4 rows) of 11 meters. The trial was carried out in four replications. The experiment was carried out in accordance with GEP (NVWA-recognition; Appendix 2; details Appendix 1).

Conducted Under GLP: No Official Trial ID: -

Conducted Under GEP: $\quad$ Yes Other Trial ID: $\quad$ AGV7716

No. Guideline Description

1. $\quad$ PP 1/135(4) phytotoxicity assessment

2. $P P 1 / 152(4)$ Design and analysis of efficacy evaluation trials

3. PP 1/181(4) Conduct and reporting of efficacy evaluation trials including GEP

4. PP $1 / 2(4)$ Phytophthora infestans on potato

\subsection{Treatments}

In Table 1 the biological crop protection products used, and dose rates are presented. Applications were carried out using a CHD-sprayer with Airmix XR110.04 nozzles approximately $50 \mathrm{~cm}$ above the foliage. Sprayings were carried out with $300 \mathrm{l} / \mathrm{ha}$ and $2.5 \mathrm{bar}$.

Table 1 Treatments and biological crop protection products applied in a 7 day spray interval

\begin{tabular}{|c|c|c|c|}
\hline Code & Treatment & Active ingredient & $\begin{array}{c}\text { Dose rate } \\
\text { I or kg per ha }\end{array}$ \\
\hline$A$ & Untreated control & - & - \\
\hline \multicolumn{4}{|l|}{ B } \\
\hline \multicolumn{4}{|l|}{$\mathrm{C}$} \\
\hline \multicolumn{4}{|l|}{$D$} \\
\hline \multicolumn{4}{|l|}{$E$} \\
\hline \multicolumn{4}{|l|}{$\mathrm{F}$} \\
\hline \multicolumn{4}{|l|}{ G } \\
\hline $\mathrm{H}$ & & & \\
\hline
\end{tabular}


On 12 June 2019, the potato plants were sprayed with the different treatments for the first time (Error! Reference source not found.). Spray interval was approximately 7 days. Weather conditions at the time of spraying are given in Table 2.

Table 2 Weather conditions during spray applications

\begin{tabular}{|c|c|c|c|c|c|c|c|c|}
\hline Date & Time & ВВСН & Temp. & $\mathbf{R H}$ & wind speed & wind direction & hours dry ${ }^{1}$ & Precipitation $[6]^{2}$ \\
\hline & & & $\left({ }^{\circ} \mathrm{C}\right)$ & $(\%)$ & $(\mathrm{m} / \mathrm{s})$ & & (h) & $(\mathrm{mm})$ \\
\hline $12-6-2019$ & $11: 00$ & & 17.7 & 73 & 1.3 & $\mathrm{O}$ & 1 & 7.8 \\
\hline $19-6-2019$ & $15: 00$ & & 22.7 & 69 & 1.2 & SSW & 4 & 4.6 \\
\hline $26-6-2019$ & 9:00 & 51 & 19.3 & 91 & 3.4 & NNW & 245 & 0 \\
\hline $3-7-2019$ & $11: 00$ & 58 & 16.8 & 62 & 3.6 & WSW & 75 & 0 \\
\hline $10-7-2019$ & $11: 00$ & 65 & 15.8 & 63 & 2.0 & SSW & 1 & 4.4 \\
\hline $17-7-2019$ & $11: 00$ & 65 & 16.1 & 86 & 0.8 & E & 32 & 0 \\
\hline $24-7-2019$ & $12: 00$ & 65 & 32.0 & 40 & 2.5 & ZE & 168 & 0 \\
\hline $1-8-2019$ & $13: 00$ & 66 & 19.1 & 90 & 1.3 & SSW & 21 & 0 \\
\hline $7-8-2019$ & 9:00 & 72 & 17.8 & 85 & 2.1 & sw & 46 & 0 \\
\hline $14-8-2019$ & $14: 00$ & 72 & 19.5 & 59 & 3.2 & SSW & 4 & 1.6 \\
\hline $21-8-2019$ & $13: 00$ & 75 & 20.0 & 53 & 2.0 & SSW & 179 & 0 \\
\hline
\end{tabular}

${ }^{1}$ : Number of hours without precipitation after the spray application

2: Cumulative precipitation $(\mathrm{mm})$ in the first six hours after the spray application.

\subsection{Inoculation $P$. infestans}

The experiment was not inoculated with Phytophthora infestans. No spreader rows were present in the field. Also, no sprinkler irrigation facilitated the potato late blight epidemic. Irrigation was carried out two times due to the continuous dry weather.

\subsection{Disease observations and Yield}

Disease observations were carried out once a week. The number of infected leaves was counted, and percentage infected foliage was calculated or percentage necrotic foliage per plot was estimated. The Standard Area under Disease Progress Curve (StAUDPC) was calculated (indication for disease development during the growing season).

The crop was harvested. Rotten tubers were sorted out, weighed and counted, before storage. After storage rotten tubers were sorted out weighed and counted. The rest of the potatoes were weighed and counted. Size distribution assessment was not carried out.

\section{$2.5 \quad$ Statistics}

Analysis of variance on the parameters was made using GENSTAT $19^{\text {th }}$ Edition. The experiment was carried out with four replications in a randomised block design. Each replication consisted of a plot. Transformation of data was carried out when necessary. 


\section{Results}

In general, the weather conditions in July and August were dry. Precipitation was $36 \mathrm{~mm}$ in July and $49 \mathrm{~mm}$ in August. Furthermore, two periods of exceptionally warm weather were observed. The first being from 23 to 30 June with temperatures well over $25^{\circ} \mathrm{C}$. The second period of hot weather was measured from 22 to 30 July with temperatures up to $36.8^{\circ} \mathrm{C}$.

Due to the dry and hot weather in June and July the late blight epidemic developed moderately. By the end of August the untreated reference reached a disease severity level of almost $100 \%$ and disease assessments were stopped.

\subsection{Potato late blight severity}

Until 16 July no significant differences of potato late blight severity between treatments were observed. Data are given in Appendix 3. Based on the StAUDPC treatments E, F and G significantly controlled potato late blight. Percentage control of treatments $\mathrm{E}$, F and G was $23 \%, 47 \%$ and $67 \%$ respectively. The results are presented in Table 3, Figure 1 and Figure 2.

Table 3 Arithmetical means of potato late blight severity (\%) and back transformed logit means for the different treatments.

\begin{tabular}{|c|c|c|c|c|c|c|c|}
\hline |abel $^{1}$ & 23-jul & 30-jul & 7-aug & 15 -aug & 21-aug & 28-aug & StAUDPC \\
\hline $\bar{A}$ & 4.0 & 6.0 & 4.5 & 11.3 & $70.0 \mathrm{~cd}$ & 91.3 & $14.0 \mathrm{~d}$ \\
\hline B & 3.1 & 3.4 & 5.3 & 10.6 & $73.8 \mathrm{~cd}$ & 93.0 & $14.0 \mathrm{~d}$ \\
\hline C & 2.5 & 4.4 & 5.3 & 9.4 & $63.8 \mathrm{bc}$ & 87.5 & $12.7 \mathrm{~d}$ \\
\hline D & 3.3 & 4.3 & 6.4 & 15.0 & $71.3 \mathrm{~cd}$ & 91.3 & $14.4 \mathrm{~d}$ \\
\hline$E$ & 2.0 & 3.3 & 2.9 & 5.1 & $52.5 \mathrm{~b}$ & 87.5 & $10.8 \mathrm{c}$ \\
\hline $\mathrm{F}$ & 1.1 & 1.4 & 3.1 & 3.1 & $28.8 \mathrm{a}$ & 75.0 & $7.5 \mathrm{~b}$ \\
\hline G & 0.7 & 0.8 & 2.2 & 2.2 & $17.5 \mathrm{a}$ & 57.5 & $5.2 \mathrm{a}$ \\
\hline $\mathrm{H}$ & 0.5 & 1.2 & 3.1 & 10.6 & $77.5 \mathrm{~d}$ & 94.8 & $13.7 \mathrm{~d}$ \\
\hline Lsd & 1.6 & 3.6 & 2.3 & 7.3 & 12.4 & 14.4 & 1.9 \\
\hline F pr. & $<0.001$ & $<0.10$ & $<0.01$ & $<0.05$ & $<0.001$ & $<0.001$ & $<0.001$ \\
\hline$\left.\right|^{|a b e|^{2}}$ & 23-jul & 30-jul & 7-aug & 15-aug & 21-aug & 28-aug & StAUDPC \\
\hline$A$ & $3.6 d^{3}$ & $4.6 \mathrm{c}$ & $4.2 \mathrm{bc}$ & $9.1 \mathrm{bc}$ & 70.4 & $91.7 \mathrm{~cd}$ & 13.9 \\
\hline B & $3.0 \mathrm{~d}$ & $3.3 c$ & $4.9 \mathrm{bc}$ & $9.6 \mathrm{bc}$ & 74.1 & $93.4 \mathrm{~cd}$ & 14.1 \\
\hline C & $2.3 \mathrm{~cd}$ & $3.6 \mathrm{c}$ & $5.2 \mathrm{c}$ & $9.4 \mathrm{bc}$ & 64.1 & $88.1 \mathrm{c}$ & 12.8 \\
\hline D & $3.1 \mathrm{~d}$ & $4.0 \mathrm{c}$ & $5.3 \mathrm{c}$ & $13.4 \mathrm{c}$ & 71.4 & $91.7 \mathrm{~cd}$ & 14.4 \\
\hline$E$ & $1.9 \mathrm{~cd}$ & $2.6 \mathrm{bc}$ & $2.6 a b c$ & $3.7 a b$ & 52.7 & $87.8 \mathrm{c}$ & 10.7 \\
\hline $\mathrm{F}$ & $1.2 \mathrm{bc}$ & $1.5 a b$ & $2.6 a b c$ & $2.6 \mathrm{a}$ & 27.3 & $75.8 \mathrm{~b}$ & 7.3 \\
\hline G & $0.7 a b$ & $0.7 \mathrm{a}$ & $1.4 \mathrm{a}$ & $1.4 \mathrm{a}$ & 14.5 & 59.6 a & 4.6 \\
\hline $\mathrm{H}$ & $0.5 \mathrm{a}$ & $1.1 \mathrm{a}$ & $2.3 a b$ & $8.2 b c$ & 77.7 & $95.5 \mathrm{~d}$ & 13.8 \\
\hline Lsd & - & - & - & - & - & - & - \\
\hline F pr. & $<0.001$ & $<0.001$ & $<0.05$ & $<0.001$ & $<0.001$ & $<0.001$ & $<0.001$ \\
\hline
\end{tabular}

$\left.{ }^{1}\right)$ The upper table gives the arithmetical means, when followed by a character the values are normally distributed allowing ANOVA without transformation

${ }^{2}$ ) The lower table gives the back-transformed logit values to meet the requirements for a normal distribution.

${ }^{3}$ ) Values in columns followed by the same character are not significantly different $(P=0.05)$. 


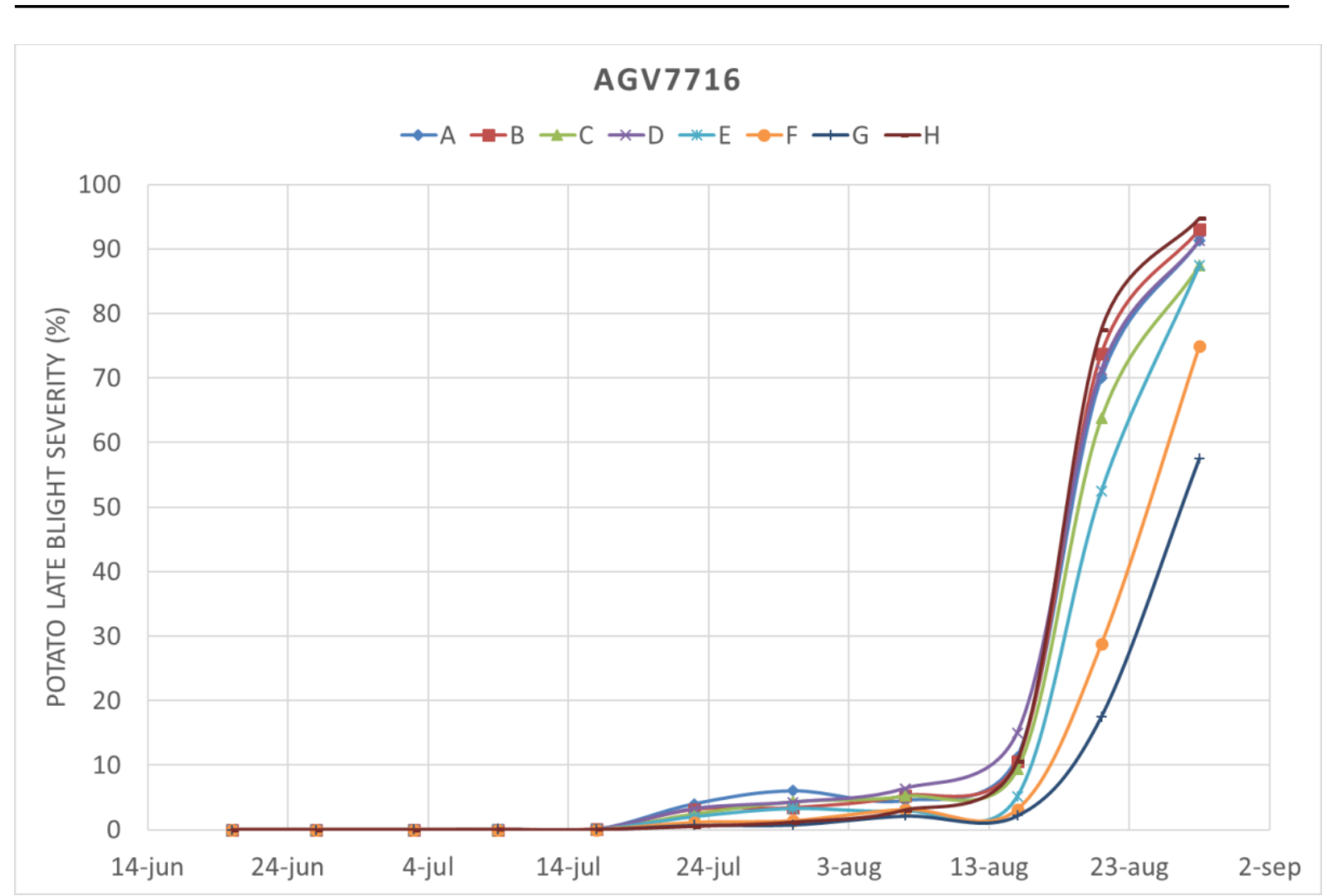

Figure 1 Potato late blight epidemic as a result of various spray schedules

AGV7716

16.0

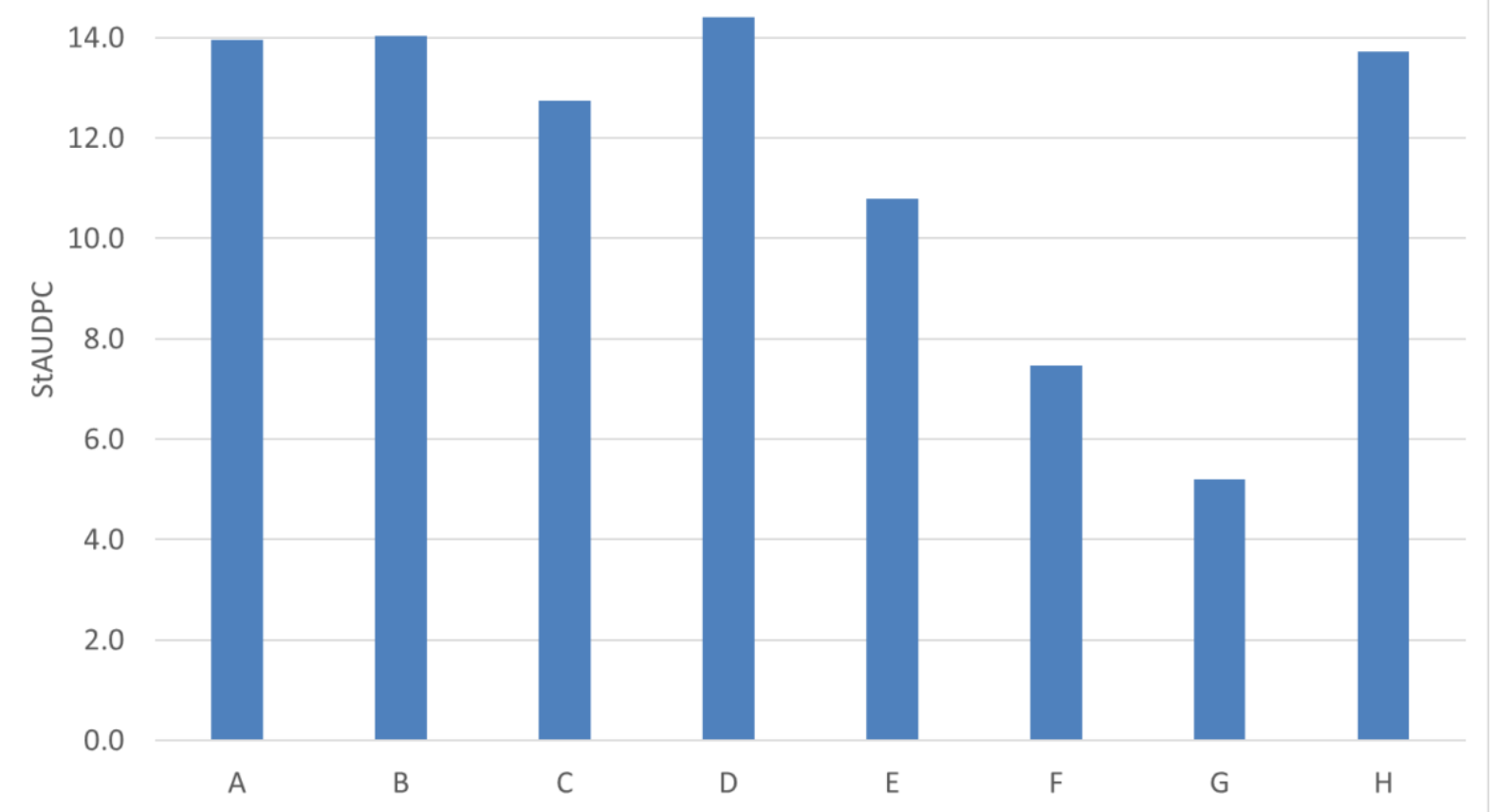

Figure 2 Potato late blight StAUDPC as a result of various spray schedules 


\subsection{Tuber blight and yield}

Tuber blight incidence (\%) in the untreated control was significantly higher than all other treatments based on number but not on weight due to high variance and low incidence (Figure 3).

Yield of the untreated control was significantly lower than treatment $\mathrm{G}$ and comparable to the other treatments (Figure 4).

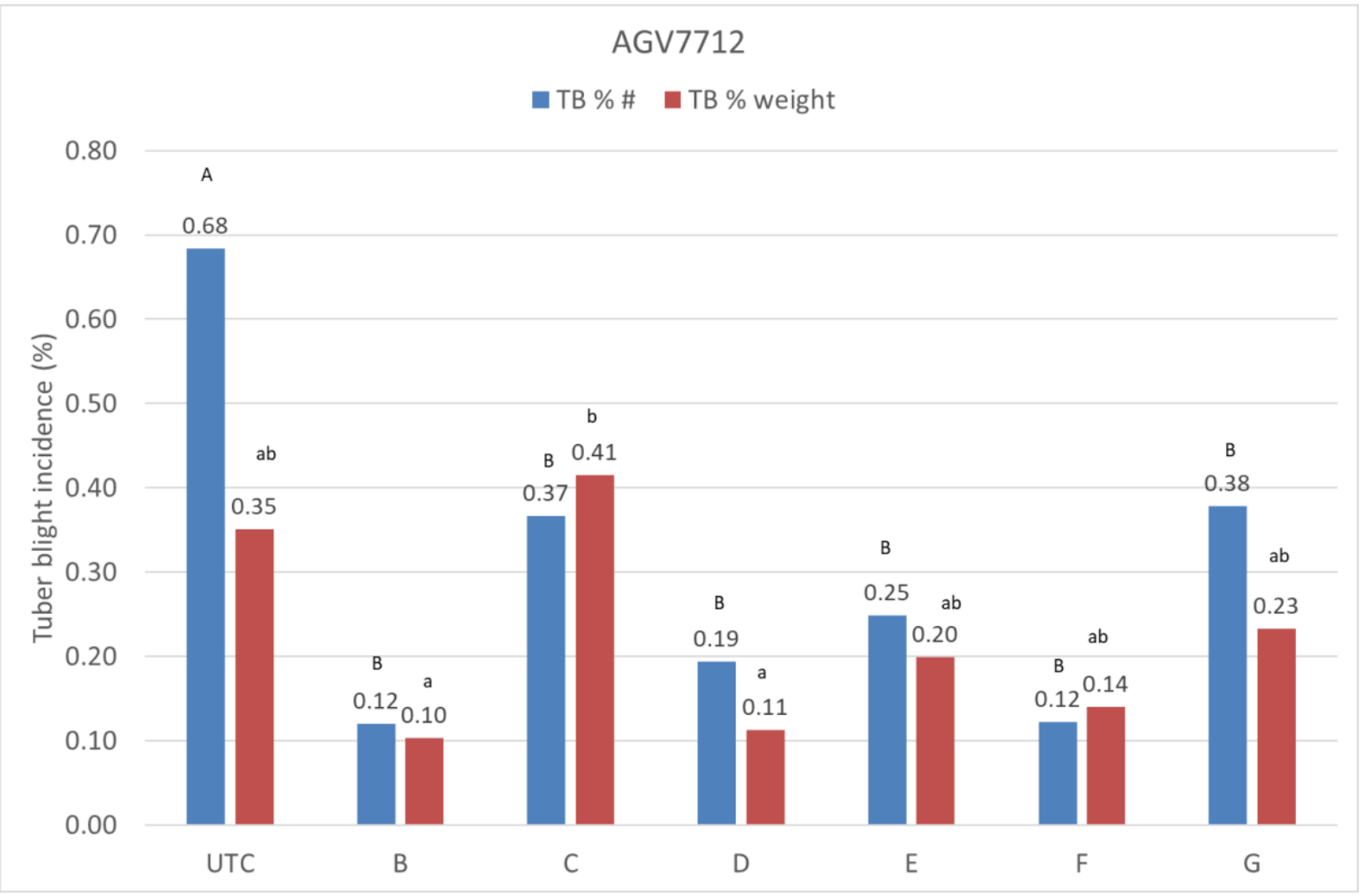

Figure 3 Tuber blight incidence (TB \%) based on number (\#) and weight as a result of various spray treatments. Values above columns followed by the same character are not significantly different $(P=0.05)$. 


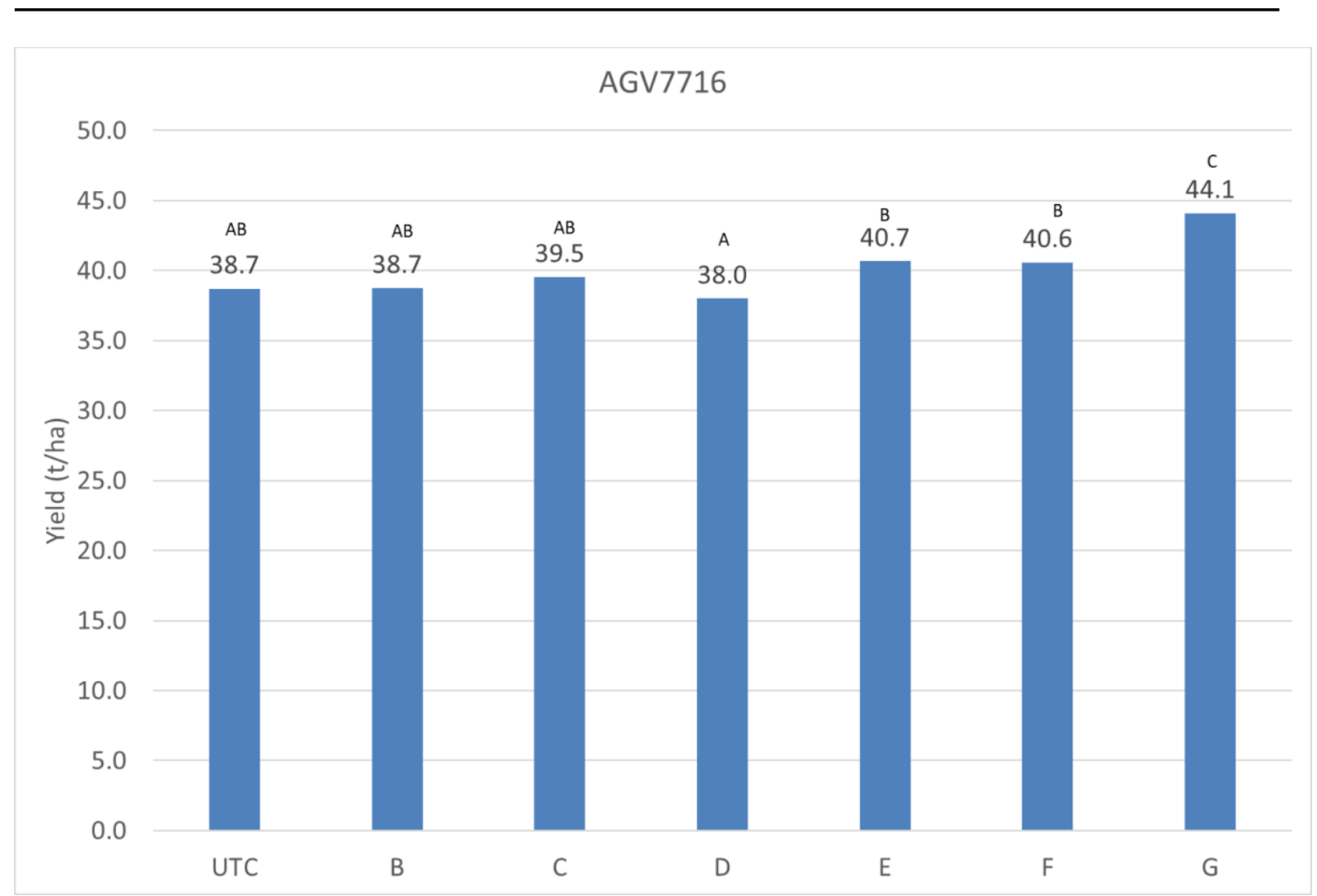

Figure 4 Yield ( $t /$ ha) as a result of the various spray treatments. Values above columns followed by the same character are not significantly different $(P=0.05)$. 


\section{$4 \quad$ Discussion and conclusions}

The experiment aimed at showing the efficacy of biological crop protection products to control potato late blight.

\subsection{Potato late blight}

The season was characterised by dry and warm weather. Potato late blight severity was very low until half August, including the untreated control. Disease pressure was not enhanced by misting of the crop and relied on natural weather circumstances. Also, no untreated spreader rows were present alongside the experiment. Furthermore no artificial inoculation was carried out. In the neighbourhood fields infected with $P$. infestans were present ensuring some disease pressure. Half August potato late blight was observed in the crop, after that the potato late blight epidemic developed strong. Basically, treatment $\mathrm{B}, \mathrm{C}, \mathrm{D}$ and $\mathrm{H}$ were not able to control $P$. infestans. In this experiment the products were sprayed in a weekly scheme not taking into account periods of infection risk. Pin point application of the biological crop protection products might have improved the efficacy, but it remains the question if this would be sufficient.

Treatments E, F and G showed some efficacy to control potato late blight. Nevertheless, disease severity was between $60 \%$ and $88 \%$ at the last assessment on 28 August. This indicates that the products might postpone the epidemic but are generally not comparable to synthetic fungicide with respect to efficacy. In organic potato production these products might prove beneficial.

\subsection{Tuber blight}

Tuber blight incidence was low and based on weighed none of the treatments were significantly different from the untreated control. Tuber blight incidence (weight) of treatments B and D were lower than treatment $\mathrm{C}$. Based on numbers, tuber blight incidence of treatment $\mathrm{B}$ to $\mathrm{G}$ were significantly lower than the untreated control comparable top each other. Weather conditions were not conducive for tuber blight since rain was limited and foliar blight severity remained low until half August. After that foliar blight increased exponentially in the following two weeks. In that period precipitation was only measured on 17 August $(7.8 \mathrm{~mm})$. Therefore, the risk period for tuber blight was limited at the time the late blight epidemic developed.

\section{$4.3 \quad$ Yield}

Total yield was around 40 t/ha which was medium yield considering the dry season. Due to foliar blight severity increasing strong in the second half of August desiccation was carried out early September. Normally in September the crop could grow and a yield of around $60 \mathrm{t} / \mathrm{ha}$ would have been possible.

Yield was affected by foliar blight. Yield of treatment $G$ was significantly higher than all other treatments. Treatments $\mathrm{E}$ and $\mathrm{F}$ gave a higher yield than treatment $\mathrm{D}$ and were comparable with the untreated control and treatments $\mathrm{B}$ and $\mathrm{C}$. 


\subsection{Conclusions}

- $\quad$ No phytotoxicity was observed, the biological crop protection products used were crop safe.

- Based on the StAUDPC treatments B, C, D and H showed no efficacy to control potato late blight, disease severity was comparable to the untreated control.

- $\quad$ Based on the StAUDPC, treatments E, F and G showed a significant efficacy to control potato late blight, where treatment $G$ performed the best, followed by treatment $F$ and in turn followed by treatment $\mathrm{E}$.

- Tuber blight incidence (\%) based on number in the untreated control was significantly higher than all other treatments ( $B$ to $G$ ).

- Yield of treatment $G$ was significantly higher than all other treatments.

- Treatments $\mathrm{E}$ and $\mathrm{F}$ gave a higher yield than treatment $\mathrm{D}$ and were comparable with the untreated control and treatments $\mathrm{B}$ and $\mathrm{C}$. 


\section{Annex 1 Trial lay-out}

Site

Soil texture:

Previous crop:

Tillage:

Fertilization:

Variety:

Planting date:

Seed Rate:

Herbicide treatment:

Fungicide application:

Alternaria treatments:

Crop desiccation:

Harvest:

Tuber assessments:

Gross plot dimensions:

Net plot dimensions:

Demo design:
Lelystad, The Netherlands 52.53 N; 5.56 E

Lelystad
Clay sandy loam

sugar beet

Conventional till

Agria

16 May 2019

$2.500 \mathrm{~kg} / \mathrm{ha}$

according to good agricultural practice

see paragraph 2.2

Narita $0.5 \mathrm{l} / \mathrm{ha} 3$ times, 14 day schedule

30 August \& 3 September

$-$

Six rows $(0.75 \mathrm{~m})$ of $11 \mathrm{~m}$ length

Two rows (0.75) of $11 \mathrm{~m}$ length

Four replications in a randomized block design 


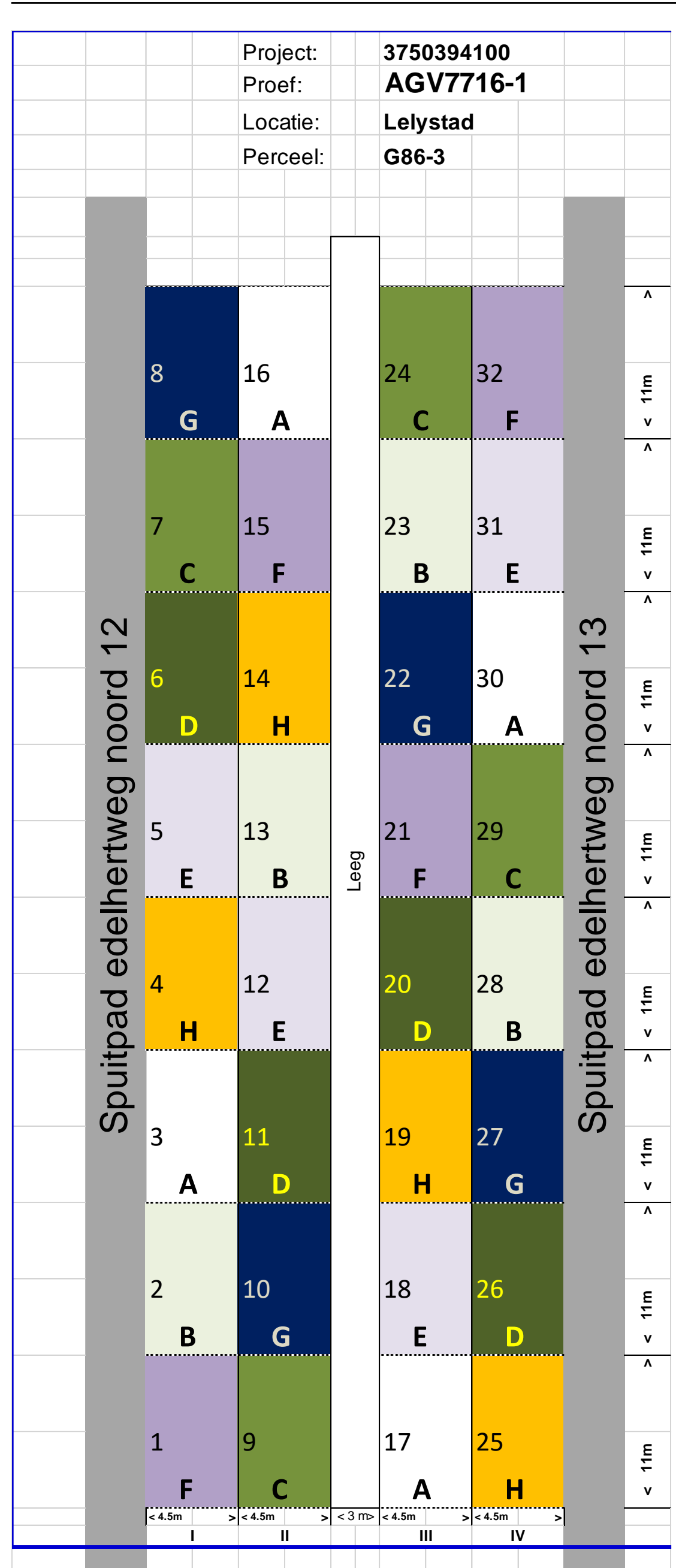




\section{Annex 2 NVWA certificate}

Netherlands Food and Consumer

Product Safety Authority

Ministry of Economic Affairs

\section{Certificate}

of Official Recognition of Efficacy Testing Organisations in the Netherlands This certifles that, in conformity with the request of March 9, 2017

\section{STICHTING WAGENINGEN RESEARCH} BUSINESS UNIT PRAKTDKONDERZOEK AGV

Residing: Edelhertweg 1 Lelystad, the Netherlands

has officially been recognised as an organisation for efficacy testing in the Netherlands.

As has been lald down in the 'Regeling gewasbeschermingsmiddelen en biociden' (Regulation Crop Protection Products and Biocides) of September 26, 2007 (Staatscourant 2007, 386).

This recognition commences on: March 1, 2017 and expires on: February 12, 2022

The above organisation is competent to carry out efficacy trials/tests in the categories mentioned in the annex of this certificate.

Utrecht, March 14, 2017

For the Minister of Economic Affairs,

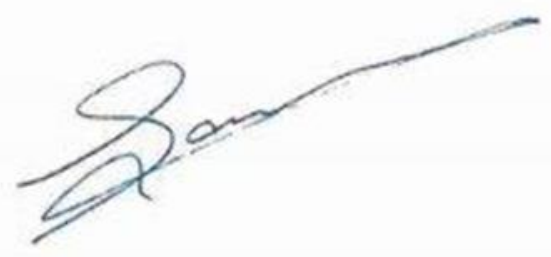

Ir. W.J.H. van der Sande Deputy Director

Netherlands Plant Protection Organization 


\section{Annex 3 Disease observations PLB}

\begin{tabular}{|c|c|c|c|c|c|c|c|c|c|c|c|c|c|c|}
\hline & \multicolumn{2}{|l|}{ Assessor: } & T & $\mathrm{T}$ & $\mathrm{T}$ & T & T & T & T & T & T & $\mathrm{T}$ & \multicolumn{2}{|l|}{$\mathrm{T}$} \\
\hline & \multicolumn{2}{|l|}{ Date: } & $20-6$ & $26-6$ & 3-7 & $9-7$ & $16-7$ & 23-7 & $30-7$ & $6-8$ & $15-8$ & $21-8$ & $28-8$ & \\
\hline \multicolumn{3}{|c|}{ Crop stage $(\mathrm{BBCH})$ : } & & 51 & 58 & 65 & 65 & 65 & 65 & 72 & 72 & 75 & 78 & \\
\hline \multicolumn{3}{|c|}{ Crop height $(\mathrm{cm})$ : } & & 50 & 50 & 60 & 60 & 60 & 60 & 70 & 70 & 70 & 70 & \\
\hline \multirow{2}{*}{\multicolumn{3}{|c|}{ iny, half cloudy, cloudy): }} & & z & z & z & $\mathrm{hb}$ & $z$ & $z$ & b & $\mathrm{b}$ & HB & z & \\
\hline & & & P. & P. & P. & P. & P. & P. & P. & P. & P. & P. & P. & \\
\hline \multirow{2}{*}{\multicolumn{3}{|c|}{$\begin{array}{l}\text { et (disease/pest/weed): } \\
\text { t level(Field/Leaf/Stem): }\end{array}$}} & infestans & infestans & infestans & infestans & infestans & infestans & infestans & infestans & infestans & infestans & infestans & \\
\hline & & & Veld & Veld & Veld & Veld & Veld & Veld & Veld & Veld & Veld & Veld & Veld & \\
\hline \multicolumn{3}{|c|}{ Assessment: } & Loof & Loof & Loof & Loof & Loof & Loof & Loof & Loof & Loof & Loof & Loof & \\
\hline \multicolumn{3}{|c|}{ Unit: } & $\%$ & $\%$ & $\%$ & $\%$ & $\%$ & $\%$ & $\%$ & $\%$ & $\%$ & $\%$ & $\%$ & \\
\hline \multicolumn{3}{|c|}{ lanner (estimate, count): } & Schatten & Schatten & Schatten & Schatten & Tellen & Schatten & Schatten & Schatten & Schatten & Schatten & Schatten & \\
\hline Field! & Object! & Blok! & Phy2006 & Phy2606 & Phy0307 & Phy0907 & Phy1607 & Phy2307 & Phy3007 & Phy0708 & Phy1508 & Phy2108 & Phy2808 & StAUDPC \\
\hline 1 & $\mathbf{F}$ & 1 & 0 & 0 & 0.01 & 0 & 0.02 & 1 & 1.5 & 1.5 & 1.5 & 25 & 75 & 6.8 \\
\hline 2 & B & 1 & 0.001 & 0.001 & 0.005 & 0.016 & 0.015 & 2 & 2.5 & 2.5 & 5 & 70 & 92 & 12.5 \\
\hline 3 & A & 1 & 0 & 0.001 & 0.01 & 0.015 & 0.015 & 3.5 & 3.5 & 3.5 & 7.5 & 75 & 90 & 13.5 \\
\hline 4 & H & 1 & 0 & 0.005 & 0.005 & 0.005 & 0.02 & 0.3 & 0.5 & 1.5 & 5 & 75 & 90 & 12.4 \\
\hline 5 & E & 1 & 0 & 0.001 & 0.001 & 0.015 & 0.03 & 2 & 2 & 2 & 2 & 45 & 85 & 9.4 \\
\hline 6 & D & 1 & 0 & 0.001 & 0.015 & 0.015 & 0.05 & 3 & 3.5 & 3.5 & 7.5 & 70 & 90 & 13.0 \\
\hline 7 & C & 1 & 0 & 0 & 0 & 0 & 0.003 & 1.5 & 2 & 3.5 & 10 & 70 & 90 & 12.9 \\
\hline 8 & G & 1 & 0 & 0.001 & 0.001 & 0.005 & 0.006 & 0.1 & 0.1 & 0.1 & 0.1 & 5 & 25 & 1.8 \\
\hline 9 & C & 2 & 0.01 & 0 & 0.007 & 0.007 & 0.01 & 1.5 & 3.5 & 5 & 7.5 & 60 & 90 & 12.1 \\
\hline 10 & G & 2 & 0 & 0 & 0.025 & 0.005 & 0.005 & 0.7 & 1 & 1.5 & 1.5 & 35 & 85 & 8.1 \\
\hline 11 & D & 2 & 0 & 0.004 & 0.01 & 0.035 & 0.035 & 5 & 7.5 & 10 & 20 & 70 & 95 & 15.9 \\
\hline 12 & E & 2 & 0 & 0.002 & 0.01 & 0.015 & 0.015 & 1.5 & 2.5 & 3.5 & 7.5 & 65 & 90 & 12.3 \\
\hline 13 & B & 2 & 0 & 0 & 0.01 & 0.015 & 0.02 & 3.5 & 3.5 & 7.5 & 10 & 80 & 95 & 15.0 \\
\hline 14 & H & 2 & 0 & 0.001 & 0.001 & 0.025 & 0.03 & 1 & 2 & 7.5 & 20 & 75 & 97 & 15.2 \\
\hline 15 & $\mathbf{F}$ & 2 & 0 & 0 & 0 & 0.005 & 0.005 & 1.5 & 1.5 & 5 & 5 & 50 & 85 & 10.4 \\
\hline 16 & A & 2 & 0 & 0.002 & 0.005 & 0.01 & 0.1 & 3.5 & 3.5 & 5 & 15 & 70 & 90 & 14.0 \\
\hline 17 & A & 3 & 0 & 0.002 & 0.015 & 0.015 & 0.015 & 1.5 & 2 & 2 & 2.5 & 60 & 95 & 11.3 \\
\hline 18 & E & 3 & 0 & 0.002 & 0.002 & 0.01 & 0.01 & 1 & 1 & 1 & 1 & 35 & 90 & 8.3 \\
\hline 19 & H & 3 & 0 & 0 & 0.001 & 0.015 & 0.025 & 0.1 & 0.7 & 0.7 & 2.5 & 80 & 95 & 12.8 \\
\hline 20 & D & 3 & 0 & 0.001 & 0.02 & 0.02 & 0.034 & 1.5 & 2.5 & 2 & 7.5 & 70 & 90 & 12.6 \\
\hline 21 & $F$ & 3 & 0 & 0.005 & 0.005 & 0.015 & 0.01 & 1 & 1.5 & 1 & 1 & 15 & 65 & 5.2 \\
\hline 22 & G & 3 & 0 & 0.01 & 0.03 & 0.03 & 0.1 & 1 & 1 & 2 & 2 & 10 & 45 & 3.9 \\
\hline 23 & B & 3 & 0 & 0.002 & 0.002 & 0.002 & 0.025 & 2 & 2.5 & 3.5 & 20 & 75 & 90 & 14.5 \\
\hline 24 & C & 3 & 0 & 0.005 & 0.015 & 0.03 & 0.03 & 2 & 2 & 5 & 10 & 55 & 80 & 11.3 \\
\hline 25 & H & 4 & 0 & 0.001 & 0.001 & 0.026 & 0.026 & 0.7 & 1.5 & 2.5 & 15 & 80 & 97 & 14.5 \\
\hline 26 & D & 4 & 0 & 0.007 & 0.007 & 0.025 & 0.025 & 3.5 & 3.5 & 10 & 25 & 75 & 90 & 16.1 \\
\hline 27 & G & 4 & 0 & 0.005 & 0.005 & 0.025 & 0.025 & 1 & 1 & 5 & 5 & 20 & 75 & 7.0 \\
\hline 28 & B & 4 & 0 & 0.002 & 0.005 & 0.005 & 0.005 & 5 & 5 & 7.5 & 7.5 & 70 & 95 & 14.1 \\
\hline 29 & C & 4 & 0 & 0.003 & 0.011 & 0.011 & 0.03 & 5 & 10 & 7.5 & 10 & 70 & 90 & 14.6 \\
\hline 30 & A & 4 & 0.005 & 0.001 & 0.001 & 0.02 & 0.045 & 7.5 & 15 & 7.5 & 20 & 75 & 90 & 16.9 \\
\hline 31 & E & 4 & 0 & 0 & 0 & 0.035 & 0.035 & 3.5 & 7.5 & 5 & 10 & 65 & 85 & 13.2 \\
\hline 32 & $F$ & 4 & 0 & 0.001 & 0.002 & 0.016 & 0.015 & 1 & 1 & 5 & 5 & 25 & 75 & 7.5 \\
\hline
\end{tabular}




\section{Annex 4 Yield and tuber blight}

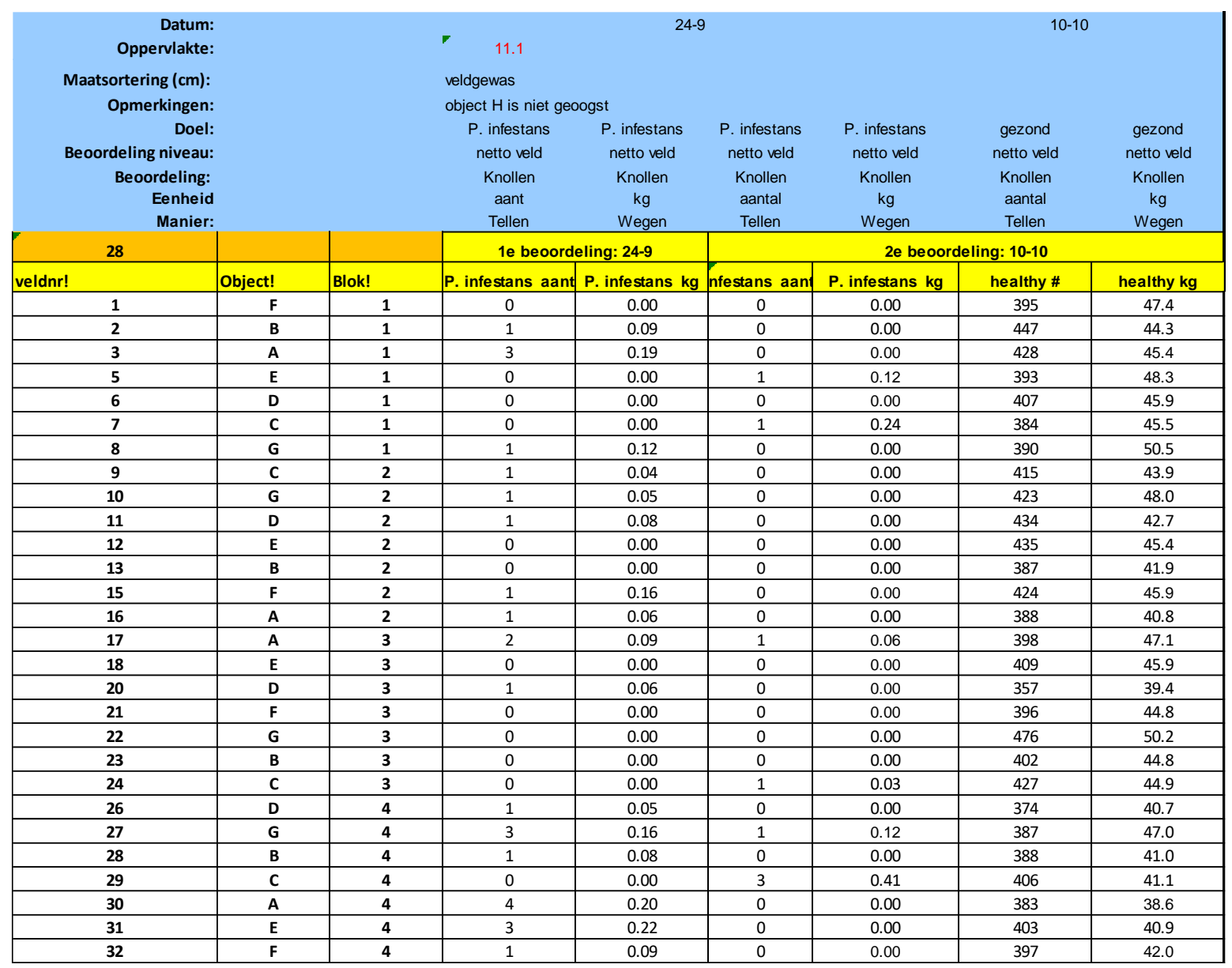




\section{Annex 5 Weather data Lelystad}

\begin{tabular}{|c|c|c|c|c|c|c|c|c|}
\hline Date & T-gem & T-max & T-min & rain & radiation & RV-min & $\begin{array}{l}\text { wind } \\
\text { direction }\end{array}$ & $\begin{array}{l}\text { wind } \\
\text { speed }\end{array}$ \\
\hline 01-05-19 & 9.2 & 10.8 & 7.4 & 0 & 0 & 73 & WNW & 0.7 \\
\hline 02-05-19 & 9.5 & 12.5 & 6.2 & 0.2 & 0 & 77 & NW & 1.5 \\
\hline 03-05-19 & 7.9 & 9.6 & 6.2 & 0.4 & 0 & 59 & NW & 1.9 \\
\hline 04-05-19 & 7.1 & 9.3 & 5.6 & 0.8 & 0 & 53 & $\mathrm{~N}$ & 3.1 \\
\hline $05-05-19$ & 7.4 & 10.1 & 4.7 & 0.2 & 0 & 57 & WNW & 2.4 \\
\hline 06-05-19 & 7.5 & 10.3 & 5.7 & 2.4 & 0 & 56 & NW & 1.3 \\
\hline 07-05-19 & 8.2 & 11.5 & 4.8 & 0 & 0 & 58 & SE & 0.7 \\
\hline 08-05-19 & 9.1 & 12.8 & 5.2 & 0.6 & 0 & 59 & SSE & 0.9 \\
\hline 09-05-19 & 11.3 & 15.6 & 7.5 & 0 & 0 & 63 & W & 1.2 \\
\hline $10-05-19$ & 9.8 & 12 & 7.9 & 6.8 & 0 & 66 & NE & 1 \\
\hline $11-05-19$ & 8.9 & 12.5 & 4.9 & 0 & 0 & 54 & ESE & 1.3 \\
\hline $12-05-19$ & 9.4 & 12 & 6.7 & 0 & 0 & 63 & NNE & 1.4 \\
\hline $13-05-19$ & 8.9 & 12.5 & 3.3 & 0 & 0 & 53 & NNE & 0.9 \\
\hline $14-05-19$ & 10.5 & 15.4 & 5.5 & 0 & 0 & 42 & NNE & 0.8 \\
\hline $15-05-19$ & 11.3 & 16.1 & 5.5 & 0 & 0 & 31 & NE & 0.6 \\
\hline $16-05-19$ & 11.1 & 16.5 & 6.4 & 0 & 0 & 38 & NNE & 0.8 \\
\hline $17-05-19$ & 12.1 & 14.2 & 10 & 0.8 & 0 & 62 & NNE & 0.6 \\
\hline $18-05-19$ & 13.9 & 19.1 & 9.9 & 0.2 & 0 & 57 & NNW & 0.7 \\
\hline $19-05-19$ & 13.7 & 17.3 & 10.9 & 4 & 0 & 87 & NNW & 1.2 \\
\hline 20-05-19 & 12.7 & 14.4 & 12 & 0 & 0 & 99 & NW & 1 \\
\hline $21-05-19$ & 11.8 & 12.7 & 11.2 & 0 & 0 & 98 & NW & 1.7 \\
\hline $22-05-19$ & 12.7 & 16 & 10.4 & 0 & 0 & 64 & $\mathrm{~N}$ & 0.8 \\
\hline $23-05-19$ & 14 & 19.8 & 7.9 & 0 & 0 & 45 & NW & 0.8 \\
\hline 24-05-19 & 13.7 & 18.7 & 9.4 & 0 & 0 & 62 & $\mathrm{~N}$ & 1.1 \\
\hline $25-05-19$ & 12.9 & 15.2 & 10.6 & 0 & 0 & 67 & WNW & 0.9 \\
\hline $26-05-19$ & 15 & 19.6 & 9.3 & 7.8 & 0 & 64 & WSW & 1.7 \\
\hline 27-05-19 & 14.1 & 16.5 & 11.5 & 1.4 & 0 & 55 & WNW & 1.6 \\
\hline $28-05-19$ & 11.6 & 14.3 & 9 & 0 & 0 & 59 & $\mathrm{~N}$ & 1.5 \\
\hline 29-05-19 & 12.4 & 17.8 & 4.7 & 0 & 0 & 36 & WSW & 0.9 \\
\hline $30-05-19$ & 15.7 & 19.4 & 12.2 & 0 & 0 & 67 & SSW & 1.7 \\
\hline $31-05-19$ & 17.1 & 19.7 & 14.4 & 0 & 0 & 64 & $\mathrm{~S}$ & 1.4 \\
\hline 01-06-19 & 17.1 & 21.5 & 11.6 & 0 & 0 & 65 & $E$ & 0.8 \\
\hline 02-06-19 & 21.9 & 28.9 & 14.4 & 0 & 0 & 38 & SW & 1.1 \\
\hline 03-06-19 & 17.3 & 19.5 & 15.1 & 0 & 0 & 53 & NNW & 0.9 \\
\hline 04-06-19 & 18.2 & 23.3 & 12.3 & 22 & 0 & 39 & SSE & 0.8 \\
\hline 05-06-19 & 16.6 & 18.5 & 14.6 & 0.8 & 0 & 74 & SE & 1.5 \\
\hline $06-06-19$ & 14.8 & 17.2 & 12.1 & 5.6 & 0 & 53 & ENE & 1.6 \\
\hline 07-06-19 & 15.1 & 21.6 & 10.1 & 0.2 & 0 & 52 & SSE & 0.8 \\
\hline 08-06-19 & 14 & 16.5 & 12.1 & 1.8 & 0 & 55 & SSW & 2.3 \\
\hline 09-06-19 & 14.1 & 18.6 & 9.5 & 0 & 0 & 53 & NNE & 0.9 \\
\hline $10-06-19$ & 16.6 & 21.7 & 12.3 & 20.6 & 0 & 61 & $\mathrm{~N}$ & 0.9 \\
\hline $11-06-19$ & 15.1 & 17.9 & 12.6 & 1.4 & 0 & 65 & NNW & 0.7 \\
\hline
\end{tabular}




\begin{tabular}{|c|c|c|c|c|c|c|c|c|}
\hline $12-06-19$ & 12.7 & 17.7 & 3.5 & 7.8 & 0 & 24 & $\mathrm{~S}$ & 0.7 \\
\hline $13-06-19$ & 13 & 17 & 4.6 & 2.6 & 0 & 31 & SSE & 1.2 \\
\hline $14-06-19$ & 14.9 & 22 & 4.8 & 1.4 & 0 & 32 & ESE & 0.8 \\
\hline $15-06-19$ & 13.7 & 17.9 & 3.8 & 6.2 & 0 & 25 & WSW & 0.6 \\
\hline $16-06-19$ & 15.8 & 19.9 & 9 & 1 & 0 & 39 & WSW & 0.7 \\
\hline $17-06-19$ & 18.2 & 23.7 & 12.2 & 0 & 0 & 54 & NNE & 0.7 \\
\hline $18-06-19$ & 18.8 & 23.3 & 13.5 & 0 & 0 & 63 & NNE & 0.7 \\
\hline $19-06-19$ & 18.4 & 22.9 & 14.9 & 7.2 & 0 & 69 & SSE & 0.8 \\
\hline $20-06-19$ & 16.5 & 18.7 & 14.6 & 6.2 & 0 & 72 & SW & 0.9 \\
\hline 21-06-19 & 15.2 & 18.7 & 11.7 & 0 & 0 & 61 & NNW & 1.1 \\
\hline $22-06-19$ & 15.8 & 20.4 & 9.4 & 0 & 0 & 59 & NNE & 0.9 \\
\hline $23-06-19$ & 20.8 & 28.2 & 13.6 & 0 & 0 & 42 & $E$ & 0.8 \\
\hline 24-06-19 & 24.5 & 30.4 & 18.2 & 0 & 0 & 46 & ESE & 1.9 \\
\hline $25-06-19$ & 25.8 & 32.1 & 20.1 & 0 & 0 & 47 & WNW & 1.4 \\
\hline $26-06-19$ & 19.1 & 22.7 & 15.3 & 0 & 0 & 76 & $\mathrm{~N}$ & 3.5 \\
\hline $27-06-19$ & 15.1 & 17.7 & 12.3 & 0 & 0 & 71 & $\mathrm{~N}$ & 2.8 \\
\hline $28-06-19$ & 16.9 & 22.7 & 13.2 & 0 & 0 & 56 & $\mathrm{NE}$ & 1.2 \\
\hline 29-06-19 & 21.8 & 30.8 & 12.1 & 0 & 0 & 34 & SSE & 0.9 \\
\hline $30-06-19$ & 20.2 & 22.7 & 16.8 & 0 & 0 & 63 & SSW & 1.2 \\
\hline 01-07-19 & 17.4 & 19.6 & 14.8 & 0 & 0 & 59 & WSW & 1.8 \\
\hline 02-07-19 & 16.6 & 19 & 14 & 0 & 0 & 57 & NNW & 3.3 \\
\hline 03-07-19 & 15.1 & 17.7 & 11.9 & 0 & 0 & 58 & $\mathrm{~N}$ & 3.1 \\
\hline 04-07-19 & 15.4 & 20.2 & 9.7 & 0 & 0 & 58 & SSW & 1.6 \\
\hline 05-07-19 & 17.8 & 21 & 14.4 & 0 & 0 & 55 & NW & 2.3 \\
\hline 06-07-19 & 15.6 & 19.2 & 13.5 & 3.4 & 0 & 73 & NW & 2.5 \\
\hline 07-07-19 & 14.2 & 16.6 & 12.7 & 0.2 & 0 & 60 & NW & 3.3 \\
\hline 08-07-19 & 13.6 & 15.2 & 12.3 & 0.4 & 0 & 69 & SW & 3.7 \\
\hline 09-07-19 & 14.4 & 17.1 & 12 & 0.4 & 0 & 59 & $\mathrm{NE}$ & 2.8 \\
\hline $10-07-19$ & 13.3 & 15.8 & 10.2 & 4.6 & 0 & 63 & SSE & 1.6 \\
\hline $11-07-19$ & 16.9 & 20.5 & 14 & 3.6 & 1.273 & 79 & WNW & 1.6 \\
\hline $12-07-19$ & 16.3 & 20.3 & 13.7 & 4.6 & 3.104 & 84 & NNW & 1.7 \\
\hline $13-07-19$ & 16.2 & 18.4 & 14.7 & 0.2 & 4.6 & 73 & NW & 3.5 \\
\hline $14-07-19$ & 14.8 & 17 & 13.3 & 0.6 & 4.993 & 72 & NNE & 3.4 \\
\hline $15-07-19$ & 14.4 & 16.4 & 13.1 & 0 & 3.779 & 73 & NNW & 2.7 \\
\hline $16-07-19$ & 14.9 & 17.1 & 12.6 & 0 & 3.264 & 73 & $\mathrm{~N}$ & 1.6 \\
\hline $17-07-19$ & 15.8 & 22 & 10.3 & 0 & 7.143 & 55 & $\mathrm{~N}$ & 1 \\
\hline $18-07-19$ & 18.2 & 22.8 & 14.1 & 0.8 & 5.26 & 52 & SW & 2.3 \\
\hline $19-07-19$ & 18.5 & 22.8 & 13.6 & 0 & 5.422 & 50 & ESE & 1.2 \\
\hline 20-07-19 & 18.9 & 22.4 & 16.5 & 4.2 & 3.838 & 71 & SW & 2.7 \\
\hline 21-07-19 & 18.4 & 21.5 & 15.2 & 0 & 7.45 & 47 & NW & 2.2 \\
\hline $22-07-19$ & 19.5 & 25.5 & 13.7 & 0 & 6.315 & 58 & SW & 1.8 \\
\hline $23-07-19$ & 22.3 & 28.3 & 14.9 & 0 & 8.15 & 50 & NNE & 1.3 \\
\hline 24-07-19 & 25.7 & 35.2 & 17.4 & 0 & 7.681 & 27 & NNW & 1.1 \\
\hline $25-07-19$ & 27 & 36.8 & 17 & 0 & 7.281 & 34 & $\mathrm{NE}$ & 1.2 \\
\hline 26-07-19 & 29 & 35.1 & 23.8 & 0 & 7.43 & 28 & NNW & 1.9 \\
\hline 27-07-19 & 24.7 & 30.9 & 19.8 & 0 & 6.703 & 33 & WNW & 1.4 \\
\hline $28-07-19$ & 20.7 & 26.1 & 18.2 & 0 & 5.047 & 58 & SW & 1.1 \\
\hline $29-07-19$ & 19.8 & 24 & 16 & 0 & 7.436 & 46 & NNE & 1.2 \\
\hline $30-07-19$ & 21.7 & 28.1 & 15.9 & 0 & 7.1 & 35 & $\mathrm{~N}$ & 1.5 \\
\hline
\end{tabular}




\begin{tabular}{|c|c|c|c|c|c|c|c|c|}
\hline $31-07-19$ & 17.7 & 20.6 & 15.9 & 13 & 3.542 & 64 & $\mathrm{~S}$ & 1.4 \\
\hline 01-08-19 & 17.4 & 20.8 & 14.3 & 1.4 & 4.401 & 73 & SW & 1.2 \\
\hline 02-08-19 & 17.4 & 19.8 & 15.7 & 5.2 & 3.14 & 83 & ESE & 1.3 \\
\hline 03-08-19 & 17.5 & 19.5 & 15.5 & 0 & 2.754 & 72 & NNW & 1.1 \\
\hline 04-08-19 & 18.1 & 22.9 & 13.2 & 0 & 5.611 & 58 & ENE & 0.8 \\
\hline 05-08-19 & 19.6 & 23.1 & 16.7 & 0 & 5.365 & 59 & SW & 1.5 \\
\hline $06-08-19$ & 18.8 & 22 & 14.9 & 0 & 5.814 & 57 & SE & 1.1 \\
\hline 07-08-19 & 18.8 & 22 & 15.6 & 0 & 6.683 & 57 & SSW & 1.4 \\
\hline 08-08-19 & 18.5 & 22.5 & 14.8 & 0 & 5.916 & 54 & NW & 1.4 \\
\hline 09-08-19 & 17.4 & 21.7 & 12.5 & 4.8 & 1.987 & 90 & SSW & 1 \\
\hline $10-08-19$ & 19.8 & 22.1 & 17.8 & 0 & 4.878 & 53 & SSW & 3 \\
\hline $11-08-19$ & 17.7 & 20.9 & 14.4 & 0 & 4.448 & 55 & SSW & 2.1 \\
\hline $12-08-19$ & 15.6 & 18.9 & 13.5 & 2 & 3.715 & 76 & WNW & 1.3 \\
\hline $13-08-19$ & 14.4 & 17.4 & 11.5 & 5 & 4.9 & 65 & SW & 1.1 \\
\hline $14-08-19$ & 15.1 & 20.6 & 9.9 & 5.6 & 5.747 & 51 & SSE & 2 \\
\hline $15-08-19$ & 16.6 & 19.4 & 14.4 & 15 & 3.695 & 79 & W & 2.3 \\
\hline $16-08-19$ & 16.7 & 20.5 & 11.6 & 0 & 4.502 & 63 & $\mathrm{~S}$ & 1.5 \\
\hline $17-08-19$ & 17.2 & 19.3 & 15.6 & 7.8 & 2.801 & 85 & SSW & 2.2 \\
\hline $18-08-19$ & 16.3 & 19.2 & 14.8 & 0.2 & 3.017 & 70 & SSW & 1.7 \\
\hline $19-08-19$ & 16.4 & 20.3 & 13.1 & 0 & 6.038 & 52 & WSW & 2.5 \\
\hline $20-08-19$ & 15.9 & 19.9 & 12.2 & 0.2 & 5.291 & 58 & $\mathrm{~S}$ & 1.9 \\
\hline 21-08-19 & 15.7 & 20.9 & 10.5 & 0 & 5.412 & 48 & NNW & 1.1 \\
\hline $22-08-19$ & 16.8 & 22.6 & 11 & 0 & 6.723 & 50 & SSE & 1.3 \\
\hline $23-08-19$ & 17.6 & 23.5 & 11.5 & 0 & 6.545 & 50 & $\mathrm{NE}$ & 0.9 \\
\hline $24-08-19$ & 21 & 28.8 & 13.9 & 0 & 6.723 & 31 & ENE & 0.9 \\
\hline $25-08-19$ & 21.2 & 29.1 & 13.8 & 0 & 6.426 & 34 & ENE & 0.7 \\
\hline $26-08-19$ & 22.4 & 29.2 & 15.6 & 0 & 6.014 & 44 & NNE & 1.1 \\
\hline 27-08-19 & 24.3 & 31.6 & 16.6 & 0 & 5.431 & 40 & $\mathrm{~S}$ & 1 \\
\hline $28-08-19$ & 22.1 & 26.4 & 18.3 & 0 & 4.308 & 57 & WSW & 1.6 \\
\hline 29-08-19 & 19.1 & 22.1 & 15.2 & 1.8 & 4.647 & 64 & $S$ & 1.7 \\
\hline $30-08-19$ & 16.8 & 21.8 & 12.1 & 0 & 5.782 & 57 & ESE & 1.4 \\
\hline $31-08-19$ & 19.5 & 26.5 & 12.9 & 0 & 5.597 & 43 & WNW & 1 \\
\hline
\end{tabular}




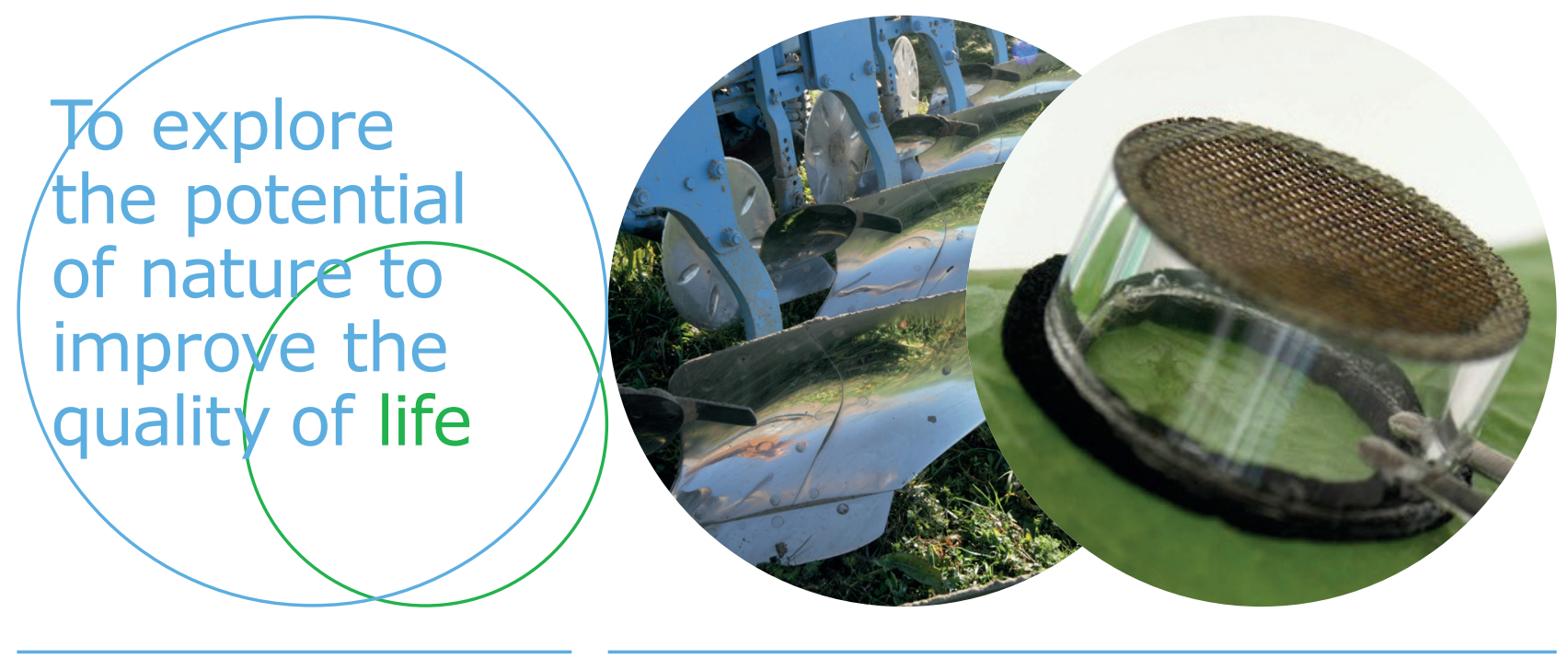

Wageningen University \& Research

\section{Open Teelten}

Edelhertweg 1

Postbus 430

8200 AK Lelystad

T (+31)3202911 11

www.wur.eu/fieldcrops

www.wur.nl/openteelten

Rapport WPR-868
The mission of Wageningen University \& Research is "To explore the potential of nature to improve the quality of life". Under the banner Wageningen University \& Research, Wageningen University and the specialised research institutes of the Wageningen Research Foundation have joined forces in contributing to finding solutions to important questions in the domain of healthy food and living environment. With its roughly 30 branches, 6,500 employees $(5,500 \mathrm{fte})$ and 12,500 students, Wageningen University \& Research is one of the leading organisations in its domain. The unique Wageningen approach lies in its integrated approach to issues and the collaboration between different disciplines. 